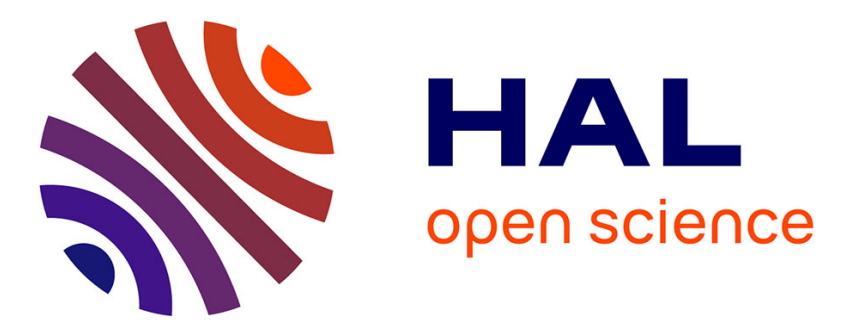

\title{
Improving the dispersion kinetics of a cocoa powder by size enlargement
}

\author{
To Vu, Laurence Galet, Jacques Fages, Driss Oulahna
}

\section{To cite this version:}

To $\mathrm{Vu}$, Laurence Galet, Jacques Fages, Driss Oulahna. Improving the dispersion kinetics of a cocoa powder by size enlargement. Powder Technology, 2003, 130 (1-3), pp.400-406. 10.1016/S00325910(02)00242-5 . hal-01593340

\section{HAL Id: hal-01593340 \\ https://hal.science/hal-01593340}

Submitted on 7 Feb 2018

HAL is a multi-disciplinary open access archive for the deposit and dissemination of scientific research documents, whether they are published or not. The documents may come from teaching and research institutions in France or abroad, or from public or private research centers.
L'archive ouverte pluridisciplinaire HAL, est destinée au dépôt et à la diffusion de documents scientifiques de niveau recherche, publiés ou non, émanant des établissements d'enseignement et de recherche français ou étrangers, des laboratoires publics ou privés. 


\title{
Improving the dispersion kinetics of a cocoa powder by size enlargement
}

\author{
T.O. Vu, L. Galet*, J. Fages, D. Oulahna \\ Ecole des Mines d'Albi-Carmaux, Laboratoire de Génie des Procédés des Solides Divisés, UMR CNRS 2392, Campus Jarlard, F-81013 Albi, France
}

\begin{abstract}
The efficient dispersion of powders in liquids is required in many fields. For this reason, it is useful to understand the mechanisms of dispersion and the physical properties of powders which influence the dispersion rate. Here, we have chosen to work with a low fat cocoa powder commonly used in the food industry. Firstly, we have determined the physical properties of the powder (densities, cohesion, flowability, size and surface energy) and then measured the dispersion times of cocoa in water using a novel optical method. Further experiments, using the same technique, are performed using larger grains obtained by granulating cocoa powder. It is found that the dispersion times are shorter for the granules and much shorter than the dispersion time for ungranulated powder. The dispersion times for granules increase with the size of granules
\end{abstract}

\section{Introduction}

Powders are often used in industry in the form of dispersion in a liquid. This is the case for cements, paints, pharmaceuticals and food powders. The different steps in powder dispersion are wetting, immersion, sedimentation and disintegration. These different processes are affected by the way the operation is carried out: how the powder is poured into the liquid, how mechanical energy is used to stir the liquid, and also by the physical and chemical properties of the dispersing liquid (surface tension, density and vis cosity) and by the physical and chemical properties of the powder itself (particle size, density and surface properties). The latter can be modified by granulation and have a large effect on the dispersion kinetics.

Few studies have dealt with the physicochemical param eters involved in the dispersion of a powder in a liquid. In the food industry, different authors have begun to study the use of granulation to obtain instant powders [1 5 ], but these studies often lack generality and do not deal with the importance of each parameter separately and how they interact together to control the dispersion kinetics. The study reported here is concerned with these factors.

The system chosen for study is cocoa powder in milk or water. This is an often encountered case of an insoluble,

\footnotetext{
* Corresponding author. Tel.: +33-5-63-49-32-35; fax: +33-5-63-4930-25.

E-mail address: laurence.galet@enstimac.fr (L. Galet).
}

hydrophobic, but easy to formulate powder, which is hard to disperse in milk or in water. We first present some physical characteristics of the cocoa powder, the experimental con ditions used to granulate it and the novel method used to follow the dispersion of cocoa particles in water. Finally, we show the size influence of the dispersion of cocoa granules in water.

\section{Materials and methods}

\subsection{The cocoa powder}

\subsubsection{Physical properties}

The cocoa powder used in this study has been charac terised in terms of particle size, flowability, surface free energy and various density measurements (true, aerated and packed density). The size distribution was measured with a Malvern 2000 laser diffraction instrument as a suspension in water. The true solid density was measured by means of a Micromeritics Accupyc helium pycnometer. Aerated and packed densities were measured using a Hosokawa PTN, a powder tester. The porosity was measured with a Micro meritics mercury porosimeter.

\subsubsection{Surface free energy}

Stevens' method [6,7] was used to determine the surface energy of cocoa powder. The method consists in sprinkling the powder on the surface of solutions of known surface 
Table 1

Physical properties of cocoa powder

\begin{tabular}{ll}
\hline Mean particle size $(\mu \mathrm{m})$ & $d_{50} \quad 16$ \\
Span $:\left(d_{\left.90 \quad d_{10}\right) / d_{50}}\right.$ & 2.2 \\
True density $\left(\mathrm{g} \mathrm{cm}^{3}\right)$ & $1.44 \pm 0.01$ \\
Aerated density $\left[D_{\text {aerated }}\right]\left(\mathrm{g} \mathrm{cm}^{3}\right)$ & $0.34 \pm 0.01$ \\
Aacked density $\left[D_{\text {packed }}\right]\left(\mathrm{g} \mathrm{cm}^{3}\right)$ & $0.67 \pm 0.01$ \\
Porosity (by mercury) $(\%)$ & $20 \pm 2$ \\
$I_{\text {Carr }}=\left(D_{\left.\text {packed } \quad D_{\text {aerated }}\right) / D_{\text {packed }}}\right.$ & $49 \%$ very bad flowability \\
$I_{\text {Hausner }}=D_{\text {packed }} / D_{\text {aerated }}$ & 1.96 very cohesive \\
Surface free energy $\left(\mathrm{mN} \mathrm{m}^{1}\right)$ & $40 \leq \sigma \leq 50$ \\
\hline
\end{tabular}

tension. These solutions are composed of mixtures water and isopropanol in different ratios. The value of the powder surface energy is taken to be that of the surface tension of the mixture for which the sprinkled powder is wetted in less than $1 \mathrm{~min}$.

\subsubsection{Results}

The main characteristics are summarised in Table 1. The aerated and packed densities ( $D_{\text {aerated }}$ and $D_{\text {packed }}$ ) are used to calculate the Carr and Hausner indexes $\left(I_{\text {Carr }}\right.$ and $\left.I_{\text {Hausner }}\right)$ [8], which characterise, respectively, the flowability and the cohesive forces of a powder.

$I_{\text {Carr }}=\frac{D_{\text {packed }}-D_{\text {aerated }}}{D_{\text {packed }}}$

$I_{\text {Hausner }}=\frac{D_{\text {packed }}}{D_{\text {aerated }}}$

The intraparticular porosity of cocoa powder is about $20 \%$ with a pore size range from 1 to $5 \mu \mathrm{m}$. The median particle size is quite low $(16 \mu \mathrm{m})$, but the size distribution is wide $(\operatorname{span}=2.2)$. The powder is very cohesive and the flowability is bad. The surface energy is less than surface tension of water $\left(72 \mathrm{mN} \mathrm{m}^{-1}\right)$ meaning that the cocoa powder is not wetted by water.

\subsection{Formulation}

\subsubsection{Wet granulation}

The cocoa powder was agglomerated by wet granulation in a Diosna high shear mixer granulator using the exper imental conditions given in Table 2. The binder water was added in drips, and the granules were dried in an oven at 45 ${ }^{\circ} \mathrm{C}$ for $5 \mathrm{~h}$ then separated in five size classes by sieving.

Table 2

Wet granulation conditions

\begin{tabular}{lc}
\hline Mass of cocoa powder $(\mathrm{g})$ & 200 \\
Water ratio: (mass water/mass powder) $(\%)$ & 65 \\
Water flow $\left(\mathrm{g} \mathrm{s}^{1}\right)$ & 0.62 \\
Speed rotation $(\mathrm{rpm})$ & 300 \\
Water addition time $(\mathrm{s})$ & 210 \\
Granulation temperature $\left({ }^{\circ} \mathrm{C}\right)$ & 25
\end{tabular}

Table 3

Size, mass fraction and granule porosity

\begin{tabular}{llllll}
\hline Class & $\begin{array}{l}\text { Size } \\
(\mu \mathrm{m})\end{array}$ & $\begin{array}{l}\text { Mass } \\
\text { fraction } \\
(\% \pm 0.1 \%)\end{array}$ & $\begin{array}{l}\text { Mercury } \\
\text { porosity } \\
(\% \pm 2 \%)\end{array}$ & Flowability & Cohesion \\
\hline 1 & $d<200$ & 30.0 & 21 & good & low \\
2 & $200<d<630$ & 22.1 & 17 & good & low \\
3 & $630<d<1000$ & 13.3 & 20 & good & low \\
4 & $1000<d<2000$ & 24.6 & 20 & good & low \\
5 & $2000<d$ & 9.9 & 21 & good & low \\
\hline
\end{tabular}

\subsubsection{Characteristics of the granules}

The characteristics of each granule size class are given in Table 3: mass fraction, intragranular porosity and flowabil ity properties. We can observe that the intraparticular porosity seems to be constant for all the granule size classes. The cohesion is low, and the flowability of each class is good.

\section{Dispersion time measurement}

Several different methods are currently used to measure dispersion times [1]. In particular, Crawley et al. [9] used a turbidimetric measurement, which has many advantages, e.g. simplicity, continuous on line measurements and easy calibration. However, in the case treated here, cocoa par ticles are absorbent and give opaque suspensions, thus making it difficult to observe the different phenomena involved in the dispersion and rendering conventional turbidimetry impossible. For this reason, a novel optical method based on an optical fibre bundle sensor has been used. This allows the determination of the fluctuations of volume concentrations and size in a suspension, which can be interpreted in terms of the quality of dispersion.

\subsection{Description of the optical technique used}

The technique used [10] is based on a bundle of optical fibres of which a central optical fibre emits light (Fig. 1) and the light back scattered by the particles in the suspension is collected by a six fibre crown around the central fibre. An electronic system converts the back scattered light intensity into a voltage, and a data acquisition system stores the voltage as a function of time.

This optical fibre sensor can be calibrated against solids volume fraction for quasi spherical particles. In this case, if

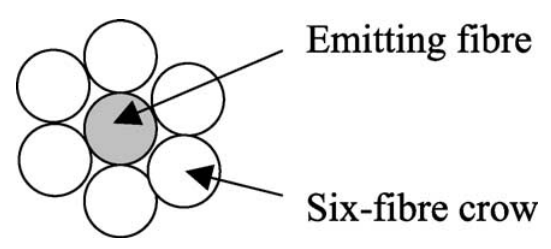

Fig. 1. Optical fibre bundle sensor. 


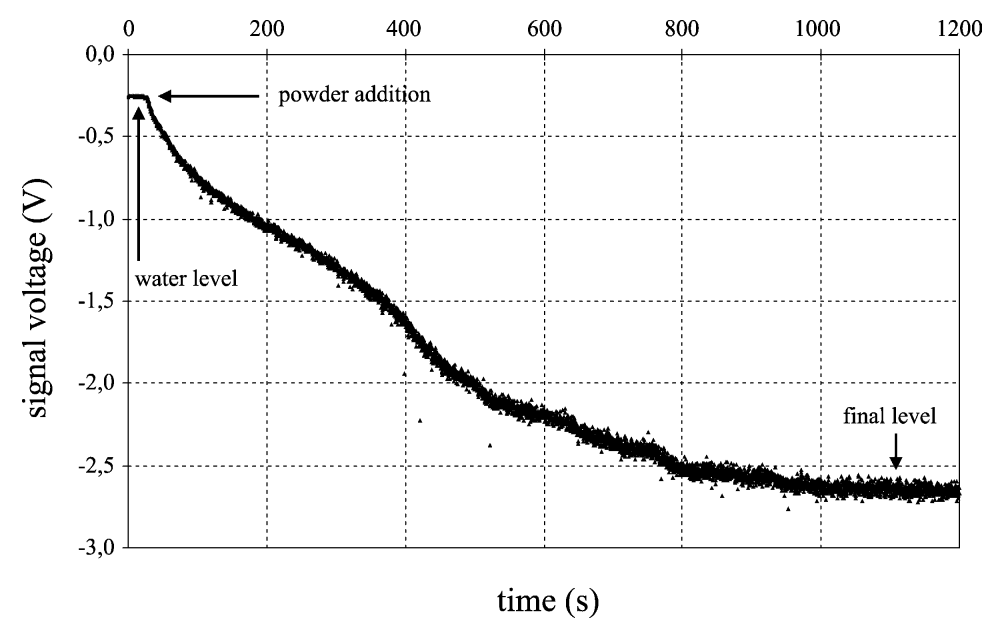

Fig. 2. Data acquisition curve for $C_{\mathrm{v}} \quad 1.03 \%$ at $470 \mathrm{rpm}$.

the volume fraction of particles is known, it is possible to obtain the mean diameter of the dispersed particles [10]. In the case here, we determine the time to obtain the final vol tage for dispersed particles in water suspension.

\subsection{Measurement conditions}

The apparatus must be calibrated with different volume ratios of cocoa. This is done by introducing a known amount of cocoa into 21 of water and thoroughly mixing by mechanical agitation until complete dispersion is ob tained. The corresponding voltage is then measured. Pre liminary experiments show no effect of the location of the optical fibre bundle in the reservoir on the dispersion ki netics.

The second step is the measurement of the dispersion time of unprocessed cocoa powder. The whole mass of cocoa is poured in one movement onto the water surface without it being aerated by sieving. This measurement is performed at room temperature $\left(22 \pm 1{ }^{\circ} \mathrm{C}\right)$ for different cocoa to water ratios. The instrument signal is observed to decrease as the powder becomes dispersed, and we stop the acquisition when a steady level is attained. Stirring is by a turbine agitator giving a mechanical energy per volume of about 90 and $870 \mathrm{~W} / \mathrm{m}^{3}$ at 470 and $1000 \mathrm{rpm}$, respectively.

An example of a signal against time curve is given in Fig. 2 corresponding to an experiment where $30 \mathrm{~g}$ of cocoa were dispersed in 21 of water $(1.03 \% \mathrm{v})$ at $470 \mathrm{rpm}$ agitation. The initial level corresponds to the water signal, and the signal decreases during dispersion to the final level, which corre sponds to the maximum dispersion attainable under the experimental conditions. $V_{\mathrm{X}^{\prime}}$ is calculated as:

$V_{\mathrm{X} \odot}=\frac{V_{\mathrm{X}}-\bar{V}_{\text {water }}}{\bar{V}_{\text {final }}-\bar{V}_{\text {water }}}$

Fig. 3 shows $V_{\mathrm{X}^{\prime}}$ versus time. A difference $\bar{V}_{\text {final }}-\bar{V}_{\text {water }}$ of $100 \%$ corresponds to total dispersion. The dispersion time is taken as the time elapsed between $90 \%$ and $10 \%$ of $\bar{V}_{\text {final }}-\bar{V}_{\text {water }}$ This method of treating the signal gives a

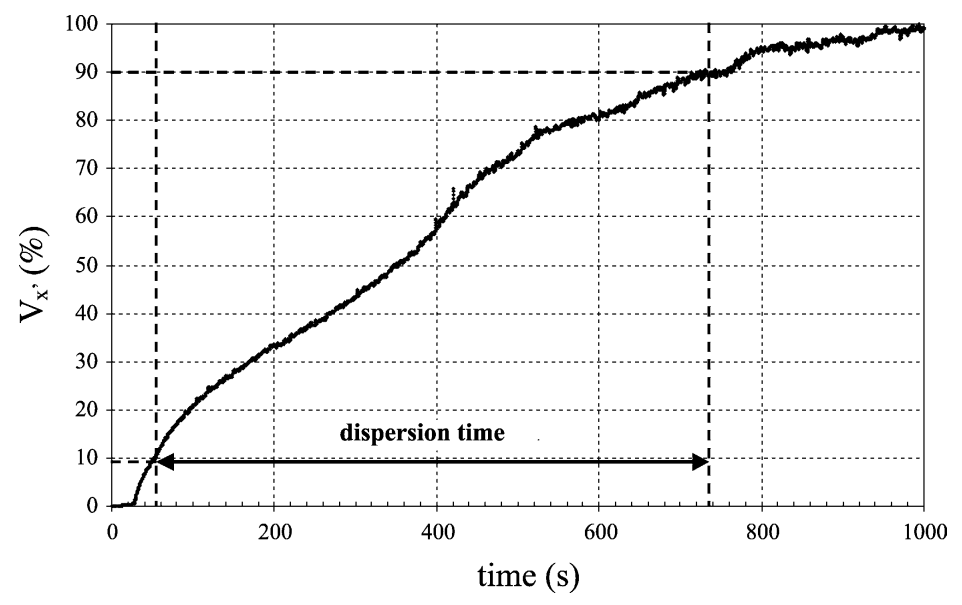

Fig. 3. Experimental dispersion curve for $C_{\mathrm{v}} \quad 1.03 \%_{\mathrm{v}}$ at $470 \mathrm{rpm}$. 


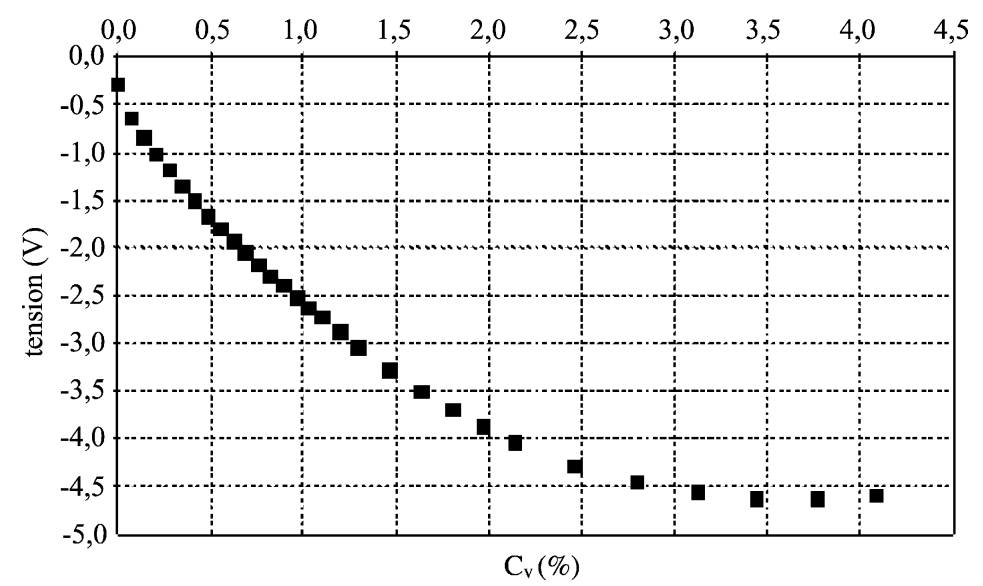

Fig. 4. Calibration curve for cocoa powder in 21 of water at $630 \mathrm{rpm}$.

precision on the determination of the dispersion time of about $5 \%$.

\section{Results and discussion}

\subsection{Calibration curve}

The calibration curve of voltage $(V)$ versus cocoa con centration (\%) obtained by successive additions of cocoa is given in Fig. 4. It can be seen that, as light is back scattered by the cocoa particles, the signal decreases as the cocoa/ water ratio increases. After a critical amount of powder has been added, the signal is saturated and the voltage no longer changes with the amount of cocoa. For the rest of this study, a concentration less than $3 \%_{\mathrm{v}}$ is used.

\subsection{Unprocessed powder}

The dispersion time and the rate of dispersion have been measured for different concentrations of cocoa $\left(C_{\mathrm{v}}\right.$ from $0.35 \%$ to $2.08 \%$ ) and for two stirrer speeds. The first stirring rate is called medium $(470 \mathrm{rpm})$ and the second is called a

Table 4

Dispersion time and dispersion rate as function of concentration (470 and $1000 \mathrm{rpm}, 21$ of water)

\begin{tabular}{|c|c|c|c|c|c|}
\hline \multicolumn{2}{|c|}{ Cocoa powder } & \multicolumn{2}{|c|}{ Dispersion time (s) } & \multirow{2}{*}{\multicolumn{2}{|c|}{$\begin{array}{l}\text { Mean dispersion rate } \\
\left(10^{2} \mathrm{~g} \mathrm{~s}^{1}\right)\end{array}$}} \\
\hline \multirow{2}{*}{$\begin{array}{l}\text { Mass } \\
(\mathrm{g})\end{array}$} & \multirow{2}{*}{$\begin{array}{l}C_{\mathrm{v}} \\
(\%)\end{array}$} & \multirow{2}{*}{$\begin{array}{l}470 \\
\mathrm{rpm}\end{array}$} & \multirow{2}{*}{$\begin{array}{l}1000 \\
\text { rpm }\end{array}$} & & \\
\hline & & & & $\begin{array}{l}470 \\
\mathrm{rpm}\end{array}$ & $\begin{array}{l}1000 \\
\mathrm{rpm}\end{array}$ \\
\hline 10 & 0.35 & 378 & 48 & 2.6 & 20.8 \\
\hline 20 & 0.69 & 616 & 62 & 3.2 & 2.3 \\
\hline 30 & 1.03 & 671 & 80 & 4.5 & 37.5 \\
\hline 40 & 1.36 & 760 & 154 & 5.3 & 26.0 \\
\hline 50 & 1.70 & $\propto$ & 16 & $\rightarrow 0$ & 312.5 \\
\hline 60 & 2.08 & $\alpha$ & 12 & $\rightarrow 0$ & 500.0 \\
\hline
\end{tabular}

high (1000 rpm). The time of dispersion (s) and the dispersion rate $\left(\mathrm{g} \mathrm{s}^{-1}\right)$ are given in Table 4 , and the curves of dispersion versus cocoa concentrations (\%) are shown in Figs. 5 and 6 . The mean dispersion rate (in $\mathrm{g} \mathrm{s}^{-1}$ ) is calculated with Eq. (4). For all experiments, the reproduci bility on the dispersion time is about $5 \%$.

$r=\frac{m_{\text {cocoa }}}{t_{\text {dispersion }}}$

At the medium stirring rate $(470 \mathrm{rpm})$, the dispersion times are long. Several minutes are required to disperse only $10 \mathrm{~g}$ of cocoa $(0.35 \%)$. From $0.35 \%$ to $1.35 \%$, the dis persion rates are very low, less than $5.3 \times 10^{-2} \mathrm{~g} \mathrm{~s}^{-1}$. We observe that the dispersion rate is small and increases slightly with the cocoa concentration. For the two higher concentrations, the powder was not at all wetted by water and some powder remained on the surface for a long time (more than $30 \mathrm{~min}$ ). A steady level is not attained, dis persion is not complete and no dispersion time can be attributed.

With high speed stirring (1000 rpm), the dispersion times are much lower and a dispersion time can be attributed for all

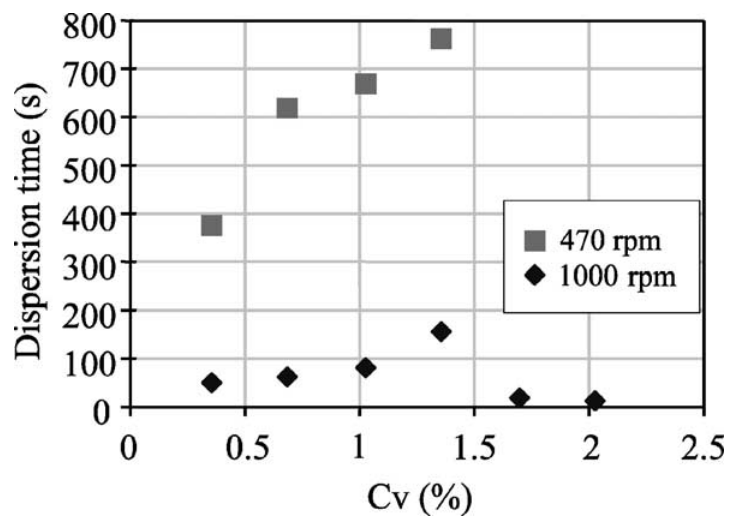

Fig. 5. Dispersion time versus concentration for 470 and $1000 \mathrm{rpm}$. 


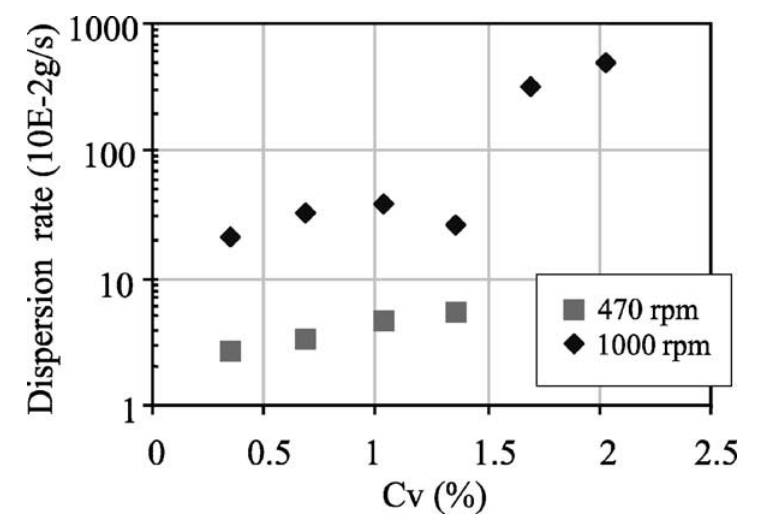

Fig. 6. Dispersion rate versus concentration for 470 and $1000 \mathrm{rpm}$.

concentrations. In this case, the dispersion time increases with all concentrations as observed at $470 \mathrm{rpm}$, except for the results at $1.7 \%_{\mathrm{v}}$ and above. High concentrations of cocoa powder give a very short dispersion time as the whole quan tity of cocoa powder penetrates directly into the water without staying on the surface. From $0.35 \%_{\mathrm{v}}$ to $1.03 \%_{\mathrm{v}}$, the disper sion rate increases with increase in concentration from $20.9 \times 10^{-2}$ to $37.5 \times 10^{-2} \mathrm{~g} \mathrm{~s}^{-1}$. At higher concentrations, the dispersion rate increases rapidly with concentration.

\subsubsection{Medium agitation speed (470 rpm)}

Fig. 5 shows that the dispersion times are very long for free cocoa powder (more than 6 min for $0.35 \%$ and more than $12 \mathrm{~min}$ for $1.35 \%$ ). In the experiment at $1.70 \%$, the dispersion time cannot be measured. In fact, mechanical stirring of $470 \mathrm{rpm}$ is insufficient to disperse cocoa powder. A bed of powder remains on the surface of water, with a viscous layer stopping capillary flow in the intergranular porosity, and the agitation is not sufficient to make the cocoa layer penetrate into the bulk liquid. This bad dispersion behaviour is caused by a number of phenomena. One is the hydrophobic nature of cocoa, the fat content being 10 $12 \%$ in cocoa powder, so that the surface energy of the powder is lower than the surface tension of water. Capillary rise experiments confirm the very low wettability of the cocoa powder. In this technique, a bed of cocoa powder $1 \mathrm{~cm}$ height $(0.5 \mathrm{~g}$ of cocoa powder into a glass column of $1 \mathrm{~cm}$ diameter supported by a thin sintered glass disk) is placed just touching a water surface, and the mass of water taken up

Table 5

Dispersion of cocoa granules $C_{\mathrm{v}} \quad 1.03 \%, 470 \mathrm{rpm}$

\begin{tabular}{llcl}
\hline Class & Size $(\mu \mathrm{m})$ & $\begin{array}{l}\text { Dispersion } \\
\text { time }(\mathrm{s})\end{array}$ & \multicolumn{2}{c}{$\begin{array}{l}\text { Dispersion rate } \\
\left(10^{2} \mathrm{~g} \mathrm{~s}^{1}\right)\end{array}$} \\
\hline 1 & $d<200$ & 88 & 33.8 \\
2 & $200<d<630$ & 299 & 10.1 \\
3 & $630<d<1000$ & 266 & 11.3 \\
4 & $1000<d<2000$ & 464 & 6.5 \\
5 & $2000<d$ & 861 & 3.5 \\
\hline
\end{tabular}

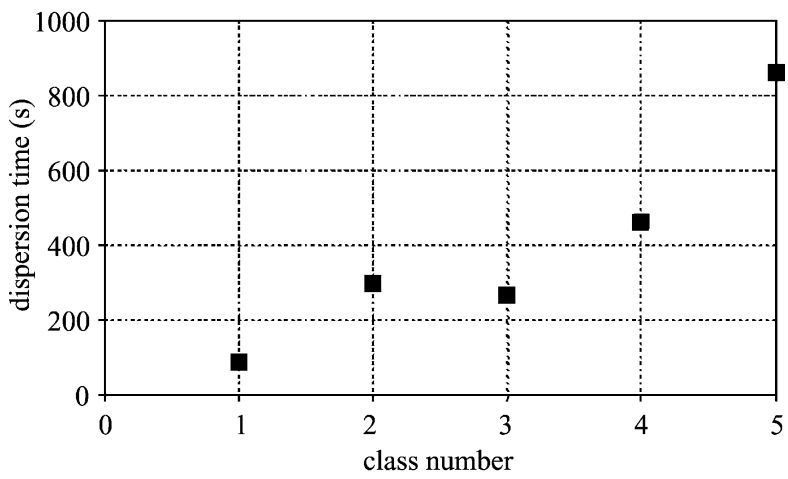

Fig. 7. Dispersion time of cocoa granules, $C_{\mathrm{v}} \quad 1.03 \%, 470 \mathrm{rpm}$.

by capillary in the cocoa powder is measured as a function of time. We observe that after $30 \mathrm{~min}$, only a small part of the cocoa powder bed is wetted by the water (less than $0.4 \mathrm{~g}$ of water in $30 \mathrm{~min}$ ).

Another factor which has an influence on the quality of dispersion is the size of the grains [3]. The smaller the grains, the more difficult is the dispersion. No penetration occurs even though the solid density is greater than the density of the water because the significant factor is the aerated and packed densities $\left(0.34\right.$ and $\left.0.67 \mathrm{~g} \mathrm{~cm}^{-3}\right)$ of the powder bed which are lower than that of water. The powder bed does not naturally penetrate the water surface, and the system requires mechanical energy.

Another reason for the bad dispersion is the bad flow ability and the cohesive forces of powder ( $I_{\text {Carr }}$ and $\left.I_{\text {Hausner }}\right)$. It seems that this cohesion causes the formation in the powder of solid agglomerates, and the shear forces are not sufficient to break the cohesive forces between grains.

\subsubsection{High agitation speed $(1000 \mathrm{rpm})$}

It can be seen in Fig. 5 that at $1000 \mathrm{rpm}$, the dispersion times for all amounts of cocoa are very low and less than for $470 \mathrm{rpm}$. There is no longer a cocoa bed on the surface whatever the concentration is, and the dispersion time increases with concentration for $470 \mathrm{rpm}$. The dispersion rate increases (Fig. 6) with concentration as the mechanical

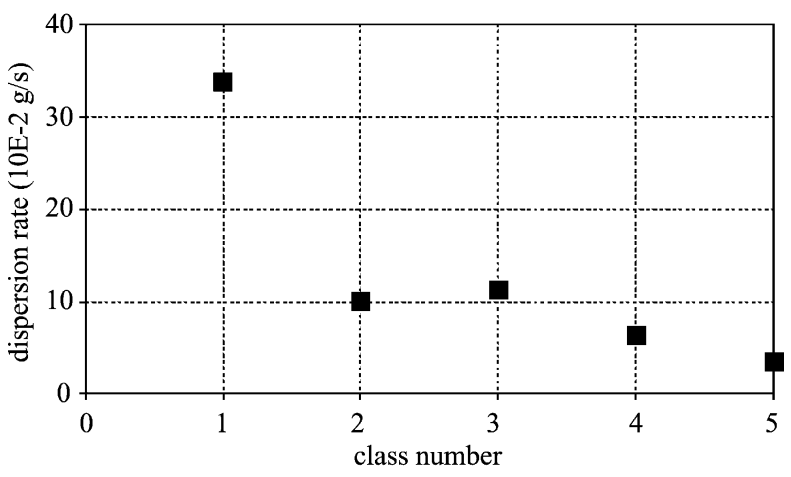

Fig. 8. Dispersion rate of cocoa granules, $C_{\mathrm{v}} \quad 1.03 \%, 470 \mathrm{rpm}$. 


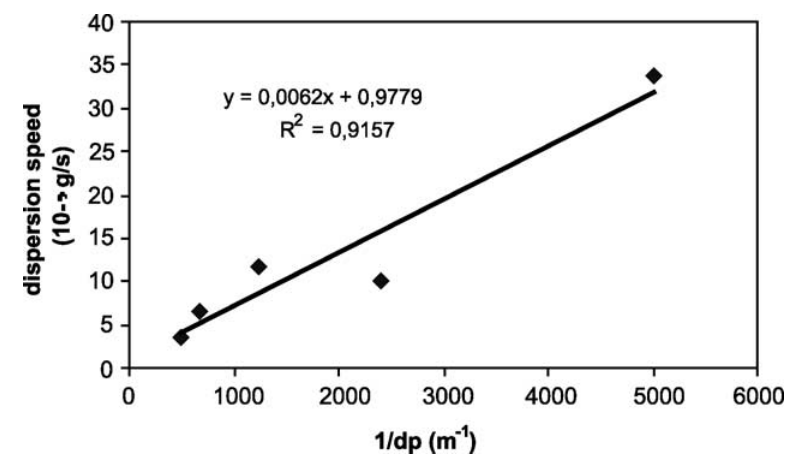

Fig. 9. Dispersion rate of cocoa granules in function of $1 / d_{\mathrm{p}}, C_{\mathrm{v}} \quad 1.03 \%$, $470 \mathrm{rpm}$.

energy is sufficient to break the cohesive interaction between the cocoa particles. The behaviour for concentra tions greater than $36 \%$ does not follow this reasoning and for the moment remains without explanation.

\subsection{Granulated cocoa powder}

Experiments have been performed with cocoa granules (see I.2.) dispersed in water at $1.03 \% \%_{\mathrm{v}}(30 \mathrm{~g}$ in 21$)$. The dis persion time and the dispersion rate were measured for each granule size class and are given in Table 5 . It should be noted that all the granules have the same intragranular porosity.

The dispersion times determined for the five granule size classes are shown in Fig. 7. It can be seen that the dispersion times increase with granule size. Dispersion time is very short for small granules (about $90 \mathrm{~s}$ are required to disperse $30 \mathrm{~g}$ of granules less than $200 \mu \mathrm{m}$ ) and quite long for big granules (about $860 \mathrm{~s}$ are required to disperse $30 \mathrm{~g}$ of granules of size greater than $2000 \mu \mathrm{m}$ ). However, there is an improvement with respect to the unprocessed powder for all classes except class $5(d>2000 \mu \mathrm{m})$. It should be noted that no undispersed granules remain in the suspension at the end of the experiment. Fig. 8 shows the corresponding change in dispersion rate with concentration.

In comparison to the unprocessed cocoa powder, the dispersion time is improved for all the granules less than $2000 \mu \mathrm{m}$. For granules of this size, the dispersion time is higher than that of the unprocessed powder at 861 and $671 \mathrm{~s}$, respectively.

In contrast to the unprocessed powder, the granules penetrate instantly into the liquid where they are broken by the mechanical agitation. The dispersion time is improved because one step is eliminated in the dispersion process. The granulated cocoa powder has a good flowability and the granules are not cohesive. Therefore, the cohesive forces be tween granules are low and shear forces at the suspension surface are sufficient to separate the granules without requir ing a high mechanical energy.

For the largest particle size class, the same phenomena occur but the breakage of these large agglomerates is more difficult and takes longer. Water penetrates into the intra particulate pores to the heart of the granule, but as the granule radius is greater, this step takes longer and is harder to do. Capillary flow into the granules is slow and breakage is not complete. This hypothesis is confirmed by the final voltage level, which is higher than the expected value, indicating that dispersion is not complete and the particle size of the dispersion is higher than the unpro cessed grain size. The dispersion time is no longer improved by an increase in granule size. It seems that dispersion depends on the external surface of the granules. Fig. 9 shows a linear evolution of the dispersion rate as a function of $1 / d_{\mathrm{p}}\left(d_{\mathrm{p}}\right.$ is the granule diameter), which is proportional to the specific surface of the granules. Before drawing a final conclusion about this relation, it is neces sary to perform further experiments with narrower size classes.

\section{Conclusion}

A novel optical method has been used to measure dispersion times and is shown to give interpretable results for a cocoa powder/water system. The method is reliable for these opaque suspensions and the measurements are accurate.

It is found that it is hard to disperse cocoa powder, but things can be improved by a greater stirrer. Dispersion rates of cocoa can be improved by using wet granulation to increase the size of particles. Further work is in progress to measure the effects of granule porosity and pore size on dispersion kinetics and on the dispersion rates for cocoa sugar mixtures.

\section{Acknowledgements}

The authors would like to thank Phoscao (Chateuneuf/ Loire, France) for providing the cocoa samples and Dr. Laurence Bergougnoux (IUSTI, Marseille, France) for her assistance in performing the optical measurements. We specially thank Laurent Devriendt (EMAC, Albi, France) for the measurements of mechanical properties of cocoa powder and one of the referees for indicating the relationship with specific surface.

\section{References}

[1] S. Hogekamp, H. Schubert, S. Wolf, Powder Technol. 86 (1996) 4957.

[2] J. Due Jansen, Manuf. Confect. 10 (1973) 4756.

[3] J. Due Jansen, Food Technol. 29 (1975) 6071.

[4] P. Kyaw Hla, Int. J. Food Sci. Technol. 34 (1999) 335342.

[5] R.K. Niven, N. Khalili, D. Brynn Hibbert, Chem. Eng. Sci. 55 (2000) 30133032 . 
[6] P. Stevens, L. Gypen, R. Jennen-Bartholomeussen, Farm. Tijdschr Belg. 51 (1974) 150155.

[7] F. Cordier, Etude de la granulation humide de poudres cosmétiques par assiette granulatrice et mélangeur à haut-cisaillement, $\mathrm{PhD}$, Ecole des Mines de Paris (2000).
[8] B. Castel, in: Techniques de l'Ingénieur, J3380, p. 6.

[9] G.M. Crawley, M. Cournil, D. Di Benedetto, Powder Technol. 91 (1997) 197208.

[10] I. Bellino, L. Bergougnoux, J. Misguich-Ripault, J.L. Firpo, Powder Technol. 115 (2001) 6874. 